\title{
Friction of metal-matrix self-lubricating composites: Relationships among lubricant content, lubricating film coverage, and friction coefficient
}

\author{
Jinkun XIAO ${ }^{1,2, *}$, Yuqing WU ${ }^{1}$, Wei ZHANG ${ }^{1}$, Juan CHEN ${ }^{3}$, Chao ZHANG ${ }^{1}$ \\ ${ }^{1}$ College of Mechanical Engineering, Yangzhou University, Yangzhou 225127, China \\ ${ }^{2}$ College of Chemistry and Chemical Engineering, Yangzhou University, Yangzhou 225002, China \\ ${ }^{3}$ Testing Center, Yangzhou University, Yangzhou 225009, China \\ Received: 06 May 2018/Revised: 30 July 2018/Accepted: 29 December 2018 \\ (C) The author(s) 2019.
}

\begin{abstract}
Metal-matrix self-lubricating composites can exhibit excellent tribological properties owing to the release of solid lubricant from the matrix and the formation of a lubricating film on the tribosurface. The coverage of the lubricating film on a worn surface significantly influences the sliding process. However, it is difficult to quantify the film coverage owing to the thin and discontinuous character of the lubricating film and the high roughness of the worn surface. A quantitative characterization of the lubricating film coverage based on X-ray photoelectron spectroscopy (XPS) analysis was developed in this study. The friction tests of $\mathrm{Cu}-\mathrm{MoS}_{2}$ composites with a $\mathrm{MoS}_{2}$ content of 0-40 vol\% were conducted, and the worn surfaces of the composites were observed and analyzed. Further, the influence of the $\mathrm{MoS}_{2}$ volume content on the coverage of the lubricating film on the worn surface was investigated. The relationships among the volume fraction of the lubricant, coverage of the lubricating film, and the friction coefficient were established. The friction model for the metal matrix self-lubricating composites was developed and verified to facilitate the composition design and friction coefficient prediction of self-lubricating composites.
\end{abstract}

Keywords: self-lubricating composites; friction coefficient; lubricating film; XPS

\section{Introduction}

Metal-matrix self-lubricating composites (MMSCs) are widely used in tribological applications wherein oil or grease lubrication cannot be implemented [1-3]. MMSCs are fabricated using two constituent components: a metal matrix and reinforced solid lubricant particles. Graphite, molybdenum disulfide, tungsten disulfide, and black phosphorus are widely used solid lubricants. They have a lamellar crystal structure with stacked layers weakly bonded with each other, while the bonding within the layers is quite strong. Thus, the shearing of the layers is easy [4-6]. MMSC is self-lubricating because of the transfer of the solid lubricant to the tribosurface and its formation into a thin film, which can prevent direct contact between the two mating surfaces. As an MMSC can maintain a continuous supply of solid lubricant to replenish the lubricating film formed at the tribosurface, it could provide effective lubrication throughout a long-term frictional operation [7-9].

The solid lubricant content significantly influences the tribological performance of MMSCs. Several researchers have found that the friction coefficient of MMSCs decreases with the increase in the lubricant content and reaches a minimum at a certain critical lubricant content [10-13]. Rohatgi et al. [14] stated that when the graphite content of metal-matrix composites

* Corresponding author: Jinkun XIAO, E-mail: jkxiao@yzu.edu.cn 


\section{Nomenclature}

$V \quad$ Volume fraction of solid lubricant

$\alpha_{\mathrm{f}} \quad$ Area fraction of lubricating film

$\mu \quad$ Friction coefficient

$\alpha_{\mathrm{m}} \quad$ Area fraction of metal matrix

$\mu_{\mathrm{m}} \quad$ Friction coefficient of metal matrix

$k \quad$ Lubricating efficiency of lubricant

$\mu_{\mathrm{f}} \quad$ Friction coefficient of lubricating film

exceeds approximately $20 \mathrm{vol} \%$, the friction coefficient approaches that of pure graphite and becomes independent of the matrix alloy. The wear resistance of MMSCs can also be greatly improved by using a certain amount of lubricant. Therefore, determining the relationship between the lubricant content and friction coefficient is essential for the design of MMSCs that provide an optimal tribological performance. Axén et al. [15] developed a model for calculating the friction of multiphase materials in abrasion. The model is based on the equal pressure or equal wear between the phases, and the total friction force is the sum of the contributions from each phase. The main limitation of the model is the consideration of only the effect of pressure and wear on the area fraction of the reinforcing phase on the worn surface. Similar models have also been proposed in other studies [7, 16]. Furthermore, the chemical composition of the surface is very different from that of the matrix after the occurrence of friction. The surface composition of MMSCs not only depends on the lubricant content, but also on the experimental conditions such as load, sliding speed, temperature, and mating surface. Hence, it is difficult to establish an accurate quantitative relationship between the composite lubricant content and the surface lubricant content.

During dry sliding, the subsurface metal undergoes severe deformation under the combined action of a normal force and friction force. The solid lubricant particles embedded in the matrix are then squeezed out and smeared to the tribosurface. The continuously smeared lubricant layers form a lubricating film on the tribosurface. It is well known that the formation of a lubricating film greatly depends on the solid lubricant content in the composite. As the lubricant content increases, a greater number of lubricant particles are released, which aids in the formation of a continuous lubricating film. Many experiments and simulations have been focused on the study of lubricating film thickness. Song et al. [17] presented a model that could predict the thickness of the lubricating film under the condition that the ceramic composite behaves macroscopically elastically, while the inclusions in the second phase material undergo locally plastic deformation. Valefi et al. [18] proposed a physical model for the process of the formation and removal of the soft layer. The model was developed based on the mechanical stresses in the soft second phase and the elastic-plastic contact between the rough and flat surfaces. Based on this model, the thickness of the soft surface layer on a ceramic substrate was predicted. $\mathrm{Xu}$ et al. [19] developed an approximate model for the migration of a solid lubricant on MMSCs. The mechanism of solid lubricant migration was investigated, and the thickness of transferred film onto the worn surface was calculated under various parameters. However, the research on the coverage of a lubricating film has progressed slowly.

Bowden et al. [20] proposed that friction was a linear function of the boundary film area fraction. Hence, the coverage of the lubricating film is an important parameter in tribology [21-24]. The film coverage has been defined as an area ratio of the tribosurface covered by the lubricant to the total tribosurface. Many works have identified that the tribosurfaces of self-lubricating composites are rich in lubricant, but the exact coverage fraction of the lubricating film on the tribosurface is unknown $[13,14]$. In order to study the influence of the lubricating film on the friction coefficient, the coverage of the lubricating film has to be quantitatively characterized. The difficulty in the characterization of the film coverage lies in the thin and discontinuous character of the lubricating film and rough worn surface. The majority of qualitative analyses of the coverage of the surface film was performed using optical or electron microscopy [25, 26]. However, a high image contrast is required between the area that is covered and not 
covered by the lubricant film. Our previous works have demonstrated that X-ray photoelectron spectroscopy (XPS) is an effective and reliable analytical method for lubricating film characterization [27, 28]. XPS has also been applied for analyzing the chemical composition and thickness of the lubricating film $[29,30]$.

Therefore, the main aim of this work is to establish the relationships among the lubricant content, lubricating film coverage, and friction coefficient for understanding the friction behavior of self-lubricating composites. A new method that can be used to quantitatively characterize the coverage of the solid lubricating film on the tribosurface of the self-lubricating composites was developed. The friction behavior of $\mathrm{Cu}-\mathrm{MoS}_{2}$ composites with a $\mathrm{MoS}_{2}$ content of $0-40 \mathrm{vol} \%$ was investigated. To identify the $\mathrm{MoS}_{2}$ lubricating film formed, the worn surfaces of $\mathrm{Cu}-\mathrm{MoS}_{2}$ composites were observed and analyzed using scanning electron microscopy (SEM) and XPS. Based on the developed XPS analysis method, the $\mathrm{MoS}_{2}$ film coverage on the worn surfaces of $\mathrm{Cu}-\mathrm{MoS}_{2}$ composites was quantitatively characterized. The friction model for the MMSCs was developed.

\section{Method for quantifying lubricating film coverage}

\subsection{Lubricating film formation and friction model}

A MMSC contains a certain amount of solid lubricant with particles homogeneously filled in the matrix. The evolution of the lubricating film on its contacting surface during sliding is illustrated in Fig. 1. Before sliding, the contact surface of the MMSC is partially covered by a solid lubricant of area fraction of $\alpha_{\mathrm{f}}$ which is equal to the volume fraction of the solid lubricant $(V)$ in the composite. During sliding, the metal matrix undergoes severe plastic deformation that is induced by the applied load and friction force. The solid lubricant particles are then squeezed out from the matrix and smeared onto the tribosurface, thus forming a lubricating film. Owing to the smearing of the lubricant particles, the coverage area of the lubricant on the tribosurface increases from $V$ to $2 \mathrm{~V}$ and even to $\mathrm{kV}$. In addition, the structure of the subsurface layer also changes, and the lubricant content in it shows an increasing trend from the composite matrix to the outmost worn surface. The outmost worn surface may not be totally covered by the lubricating film. Generally, the greater the lubricant content, the greater the amount of lubricant that is released and the larger the area fraction of the lubricating film. Hence, the area fraction of the lubricating film $\left(\alpha_{\mathrm{f}}\right)$ on the tribosurface greatly depends on the volume fraction of the solid lubricant $(V)$ in the composite, which is represented as follows:

$$
a_{\mathrm{f}}=k V
$$

where $k$ represents the lubricating efficiency of the lubricant; it indicates the ability of the solid lubricant to form a lubricating film on the worn surface during sliding. The area fraction of the metal matrix $\left(\alpha_{\mathrm{m}}\right)$ can be expressed as

$$
\alpha_{\mathrm{m}}=1-\alpha_{\mathrm{f}}
$$

Generally, the friction coefficient of MMSCs is expressed by the rule of mixture as the sum of the

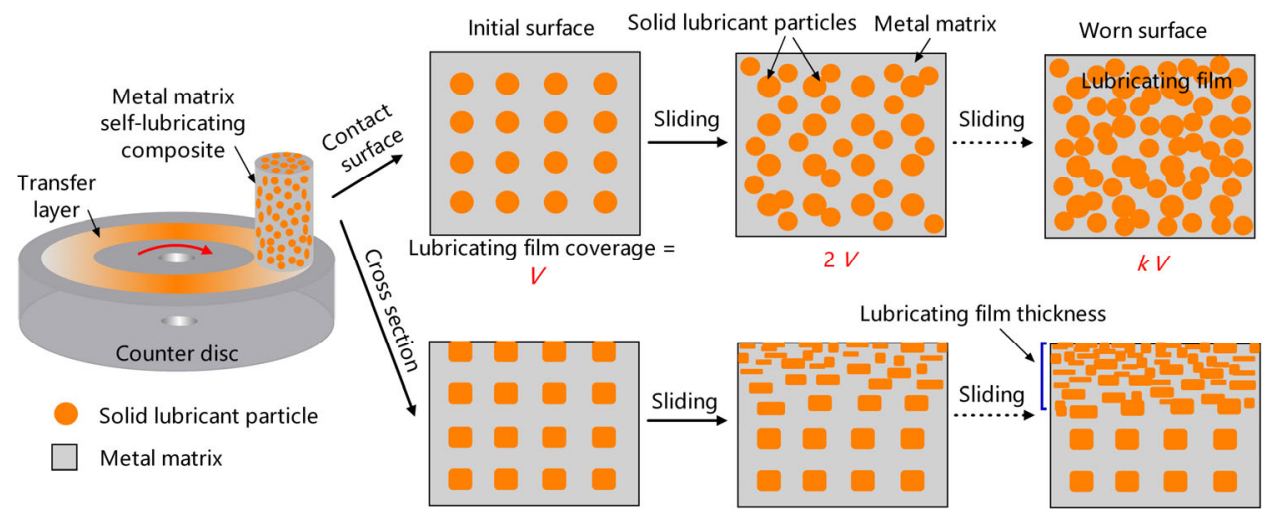

Fig. 1 Schematic showing the evolution of lubricating film on worn surface of MMSC. 
friction coefficients acting on each phase [31],

$$
\mu=\alpha_{\mathrm{m}} \mu_{\mathrm{m}}+\alpha_{\mathrm{f}} \mu_{\mathrm{f}}
$$

where $\mu_{\mathrm{m}}$ and $\mu_{\mathrm{f}}$ are the friction coefficients of the metal matrix and lubricating film, respectively. However, this equation cannot be used to describe the real phenomenon, because a transfer layer with the same composition as an MMSC is often generated on the counter surface during sliding [32].

Accordingly, the friction of the MMSC includes three contact models: metal-metal contact, metallubricating-film contact, and lubricating-film-lubricatingfilm contact [33]. The three contact models along with the related contact rates and friction coefficients of the MMSC are illustrated in Table 1. According to the classical theory of Bowden and Tabor [20], friction force is determined by the real contact area and the shear strength of the lubricant material. Therefore, the friction force of the metal-lubricating-film contact is almost equal to that of the lubricating-filmlubricating-film contact. As a result, it can be justifiably assumed that the latter two models produce the same friction coefficients as that of the lubricating film $\left(\mu_{\mathrm{f}}\right)$. Moreover, based on the results reported in the literatures, the counter surfaces of MMSCs are usually covered with continuous transfer layers, which have the same chemical composition as MMSCs; thus, the lubricating film on the transfer layer can be assumed to have an area fraction equivalent to that of the worn surface of the composite [13,28]. The contact rates for the metal-metal contact, metal-lubricating-film contact, and lubricating-film-lubricating-film contact are $\alpha_{\mathrm{m}} \alpha_{\mathrm{m}}$ $2 \alpha_{\mathrm{m}} \alpha_{\mathrm{f}}$, and $\alpha_{\mathrm{f}} \alpha_{\mathrm{f}}$, respectively. Therefore, the friction coefficient of the MMSCs can be expressed as

$$
\mu=\left(\alpha_{\mathrm{m}}^{2}\right) \mu_{\mathrm{m}}+2\left(\alpha_{\mathrm{m}} \alpha_{\mathrm{f}}\right) \mu_{\mathrm{f}}+\left(\alpha_{\mathrm{f}}^{2}\right) \mu_{\mathrm{f}}
$$

On combining Eqs. (2) and (4), we obtain

$$
\mu=\left(1-\alpha_{\mathrm{f}}\right)^{2} \mu_{\mathrm{m}}+\left(1-\left(1-\alpha_{\mathrm{f}}\right)^{2}\right) \mu_{\mathrm{f}}
$$

On combining Eqs. (1) with (5), we obtain the friction coefficient of the MMSCs:

$$
\mu=(1-k V)^{2} \mu_{\mathrm{m}}+\left(1-(1-k V)^{2}\right) \mu_{\mathrm{f}}
$$

\subsection{Quantification of lubricating film coverage using XPS}

The quantitative characterization of the lubricating film coverage is obtained using XPS. XPS is an effective and reliable analytical method for elemental identification and the quantification of the chemical states of active surface atoms because it is surfacesensitive and non-destructive. XPS analysis is performed by irradiating a sample with monoenergetic soft $X$-rays and energy analyzing the electrons emitted. The spectrum obtained is a plot of the number of emitted electrons per energy interval versus their kinetic energy. Each element has a unique elemental spectrum, and the spectral peaks from a mixture are approximately the sum of the elemental peaks from the individual constituents. The quantitative data of elements can be obtained from the peak areas. As the mean free path of the electrons is very small, the electrons that are detected originate only from the top few atomic layers. The sampling depth ( $3 \lambda$ for $\mathrm{Al} \mathrm{K} \alpha$ radiation) for the XPS is $3 \mathrm{~nm}-10 \mathrm{~nm}$, and the sampling spot size can be $15 \mu \mathrm{m}-500 \mu \mathrm{m}$. As the thickness of the lubricating film can reach hundreds of nanometers, sputter depth profiling was often used along with XPS. The compositional in-depth distribution of thin films and coatings can be directly determined using depth profiling [34-36].

The schematic of the method used for the quantitative

Table 1 Contact models of MMSC.

\begin{tabular}{cccc}
\hline Contact model & Metal-metal & (c) \\
Schematic & (a) & $2(1-k V) k V$ & $\alpha_{\mathrm{f}} \alpha_{\mathrm{f}}$ \\
Contact rate & $\alpha_{\mathrm{m}} \alpha_{\mathrm{m}}$ & $(k V)^{2}$ \\
Contact rate & $(1-k V)^{2}$ & $\mu_{\mathrm{f}}$ & $\mu_{\mathrm{f}}$ \\
Friction coefficient & $\mu_{\mathrm{m}}$ & $2 \alpha_{\mathrm{f}}$ & Metal-film \\
\hline
\end{tabular}


characterization of the lubricating film coverage using XPS analysis developed in this research is illustrated in Fig. 2. The first step of the measurement is to immediately place the samples of MMSC into the XPS instrument after the friction testing and evacuate for testing. Secondly, the first XPS analysis on the typical region of the worn surface is conducted followed by ion etching at the same position of the surface using an argon ion gun. After a few dozens of nanometers of atoms are etched from the surface, the second XPS analysis is performed on the etched area. In this manner, the processes of analysis and etching are repeated several times until no obvious change in XPS spectra is obtained. The surface layer has then been totally sputtered, and the internal microstructure of composite is exposed. No further changes in chemical composition will be observed in the depth profiling. Thus, a continuous analysis of the composition from the outmost worn surface to the internal material is achieved. The evolution of the lubricating film on the worn surface during $\mathrm{Ar}^{+}$sputtering is shown in Figs. 2(a) and 2(b). Thirdly, based on the XPS spectra, the atomic percentage of the elements on the surface can be obtained using Avantage software. The atomic percentage of elements is multiplied by the relative atomic mass to obtain the weight percentage of the elements. The weight percentages of the elements of the same compound are summed and then divided by the density of the compound. The volume fraction

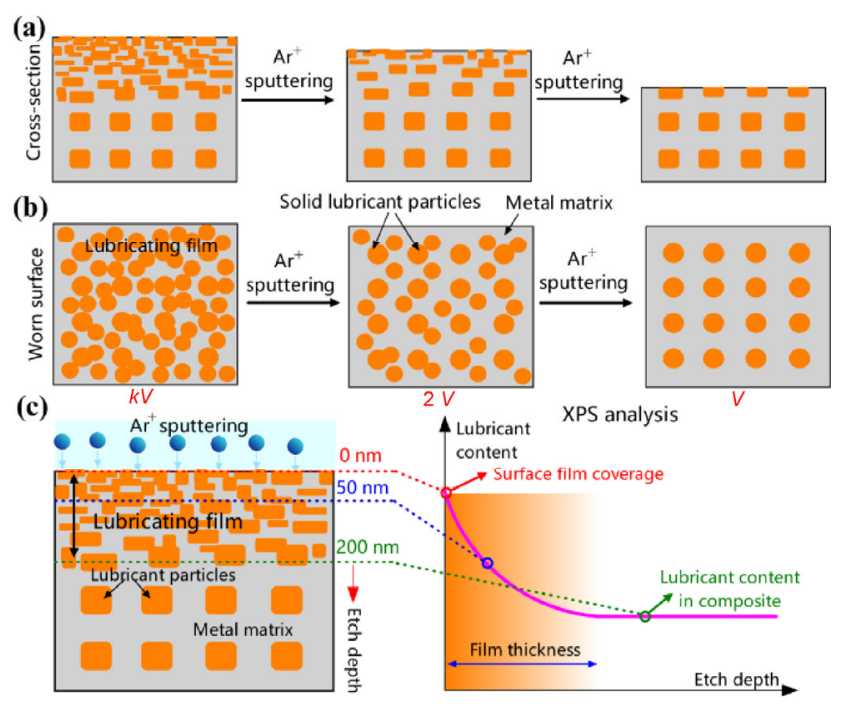

Fig. 2 Schematic illustrating the evolution of lubricating film on worn surface during $\mathrm{Ar}^{+}$sputtering process, (a) cross section of worn surface, (b) worn surface, (c) XPS analysis results. of the materials on the worn surface can then be obtained. The expected obtained XPS result is shown in Fig. 2(c). Finally, the XPS results of the lubricant content are compared in the unchanged stage with the filled lubricant content to check the accuracy of the XPS analysis. The value of the coverage fraction of the lubricating film is equal to the volume fraction of the lubricant detected on the worn surface. Therefore, the lubricating film coverage of the MMSCs can be successfully characterized using XPS analysis.

\section{Experimental details}

\subsection{Materials}

The $\mathrm{Cu}-\mathrm{MoS}_{2}$ composites with various volume fractions of $\mathrm{MoS}_{2}$ were prepared using the powder metallurgy route with hot-pressing. The copper powder was first mixed with $\mathrm{MoS}_{2}$ powder having an average partilce size of $5 \mu \mathrm{m}$ using a planetary mill. The mixed powder was then hot-pressed in a graphite die at a sintering temperature of $850{ }^{\circ} \mathrm{C}$ and pressure of $25 \mathrm{MPa}$ for $40 \mathrm{~min}$. The furnace was filled with nitrogen as a protective gas. The $\mathrm{Cu}-\mathrm{MoS}_{2}$ composites with $\mathrm{MoS}_{2}$ contents of $0,5 \mathrm{vol} \%, 10 \mathrm{vol} \%, 20 \mathrm{vol} \%, 30 \mathrm{vol} \%$, and $40 \mathrm{vol} \%$ were prepared using this method. The microstructure of the prepared $\mathrm{Cu}-\mathrm{MoS}_{2}$ composites is shown in Fig. 3. The gray areas are the $\mathrm{MoS}_{2}$ particles, and the bright area is the copper matrix. It can be observed that the $\mathrm{MoS}_{2}$ particles have a flake-like
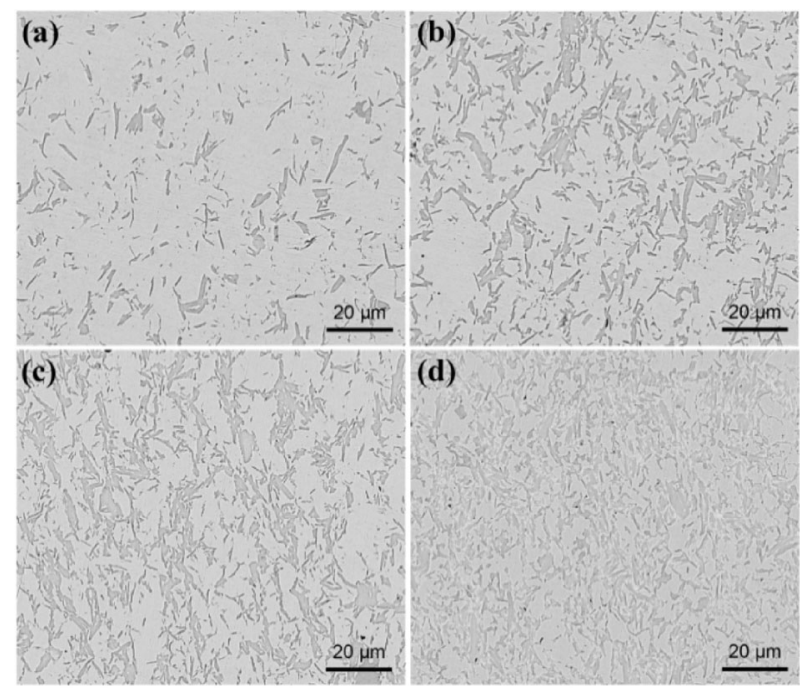

Fig. 3 Microstructure of $\mathrm{Cu}-\mathrm{MoS}_{2}$ composites with $\mathrm{MoS}_{2}$ content of (a) $10 \mathrm{vol} \%$, (b) $20 \mathrm{vol} \%$, (c) $30 \mathrm{vol} \%$, and (d) $40 \mathrm{vol} \%$. 
shape. The $\mathrm{MoS}_{2}$ particles are uniformly distributed throughout the copper matrix.

\subsection{Friction testing}

The friction experiments were performed using a tribometer (UMT-2, Bruker Instrument, USA) with a pin-on-disc configuration. The sample pins had a circular arc profile with a radius of $25 \mathrm{~mm}$. The counter disc was fabricated from beryllium copper with a diameter of $60 \mathrm{~mm}$ and hardness of $361 \mathrm{HV} 1$. The pins and discs were polished and cleaned before the testing. Sliding tests were performed at a constant normal load of $5 \mathrm{~N}$. The rotational speed was $200 \mathrm{rpm}$, and the rotational radius was set to $20 \mathrm{~mm}$. The corresponding linear speed was approximately $0.42 \mathrm{~m} / \mathrm{s}$. The sliding distance was set as $15 \mathrm{~km}$. The tests were performed in an ambient environment with an approximate temperature of $20{ }^{\circ} \mathrm{C}$ and relative humidity of $60 \%$. Three parallel tests were performed.

\subsection{Film characterization}

The morphologies of the structure and worn surfaces of the $\mathrm{Cu}-\mathrm{MoS}_{2}$ composites were investigated using a field-emission SEM (Supra 55, Zeiss, Germany) in backscatter mode to differentiate between the phases by relative density. The element distribution in the worn surfaces was analyzed using energy-dispersive X-ray spectroscopy (EDS) equipped in SEM. The worn surfaces of the $\mathrm{Cu}-\mathrm{MoS}_{2}$ composites were investigated using XPS (Escalab 250Xi system, Thermo Fisher, UK) with a monochromated Al-K $\alpha \mathrm{X}$-ray source (excitation energy $=1486.6 \mathrm{eV}$ ). The XPS analysis chamber was evacuated to a pressure of $10 \mathrm{~Pa}-6 \mathrm{~Pa}$ before the analysis. An X-ray spot size diameter on the sample of approximately $500 \mu \mathrm{m}$ was adopted. Survey spectra were acquired from $0 \mathrm{eV}-1200 \mathrm{eV}$ in the constantanalyzer-energy mode with a pass energy of $100 \mathrm{eV}$ and energy-step size of $0.5 \mathrm{eV}$. Two scans were averaged in the measurement of one spectrum. The binding energies were corrected relative to the $\mathrm{C} 1 \mathrm{~s}$ signal at $284.8 \mathrm{eV}$. The thickness of the lubricating film reached hundreds of nanometers. However, the XPS analysis could only analyze the surface with a maximum depth of $10 \mathrm{~nm}$. In order to perform the depth profiling of the worn surfaces, $\mathrm{Ar}+$ ions produced by the affiliated ion gun with an energy of $3 \mathrm{keV}$ were used for the sputtering procedure. The sputtering rate was approximately $0.33 \mathrm{~nm} / \mathrm{s}$, which was calibrated against a reference silicon oxide thin film on the silicon substrate. The sputtered area of $2.5 \mathrm{~mm} \times 2.5 \mathrm{~mm}$ was much larger than the $\mathrm{X}$-ray spot size. The accumulated etch time was set as $0 \mathrm{~s}, 25 \mathrm{~s}, 50 \mathrm{~s}, 75 \mathrm{~s}, 100 \mathrm{~s}, 150 \mathrm{~s}$, 200 s, 300 s, 500 s, 700 s, 900 s, and 1000 s, and after each etching process, a survey spectrum was collected to detect the element content. XPS data acquisition and analysis were completed using Avantage software supplied by the equipment manufacturer. Concentration quantification was performed using standard single element sensitivity factors.

\section{Results and discussion}

Figure 4 presents the backscattered electron (BSE) images and EDS mapping images of the worn surfaces of the $\mathrm{Cu}-\mathrm{MoS}_{2}$ composites with various $\mathrm{MoS}_{2}$ contents. The dark areas in the BSE images are covered by $\mathrm{MoS}_{2}$ films of a low thickness, while the bright areas are copper matrices. The distribution of the $\mathrm{MoS}_{2}$ film on the worn surfaces is also confirmed using EDS mapping. The BSE and EDS images reveal that the $\mathrm{MoS}_{2}$ film area clearly increases as the $\mathrm{MoS}_{2}$ content increases in the composites. The grooves and plastic deformation in the worn surfaces are reduced by the formation of the lubricating film. To clearly observe the distribution of the $\mathrm{MoS}_{2}$ crystals on the worn surface, a field emission SEM (FE-SEM) observation was performed, and the image of the worn surface of $\mathrm{Cu}-30-\mathrm{vol} \%-\mathrm{MoS}_{2}$ composite is shown in Fig. 5. The worn surface is coveredby a large number of $\mathrm{MoS}_{2}$ lamellae of size less than $200 \mathrm{~nm}$. Some of the $\mathrm{MoS}_{2}$ lamellae are indicatedby black arrows in Fig. 5. The $\mathrm{MoS}_{2}$ lamellae have distinct edges and corners. However, these $\mathrm{MoS}_{2}$ lamellae are very thin owing to the lamellar crystal structure. Therefore, it is difficult to characterize the coverage of the lubricating film quantitatively using the image method.

The composition evolution of the worn surfaces of the $\mathrm{Cu}-\mathrm{MoS}_{2}$ composites in depth was monitored using XPS through $\mathrm{Ar}^{+}$sputtering. The XPS survey spectra collected from the worn surfaces of the $\mathrm{Cu}-\mathrm{MoS}_{2}$ composites with various $\mathrm{MoS}_{2}$ contents are shown in Fig. 6. The survey spectra can provide elemental 


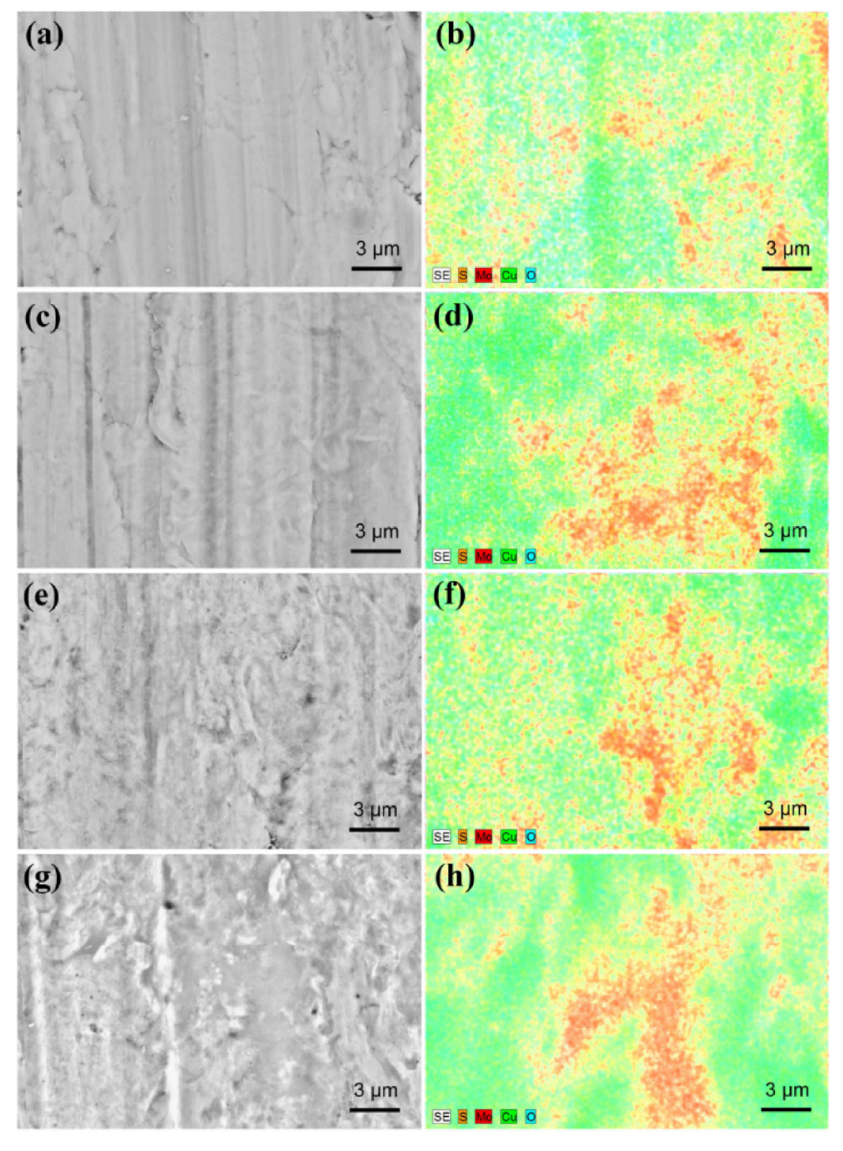

Fig. 4 BSE and EDS mapping images of worn surfaces of $\mathrm{Cu}-\mathrm{MoS}_{2}$ composites with $\mathrm{MoS}_{2}$ content of $10 \mathrm{vol} \%$ for (a) and (b), $20 \mathrm{vol} \%$ for (c) and (d), $30 \mathrm{vol} \%$ for (e) and (f), and $40 \mathrm{vol} \%$ for $(\mathrm{g})$ and $(\mathrm{h})$.

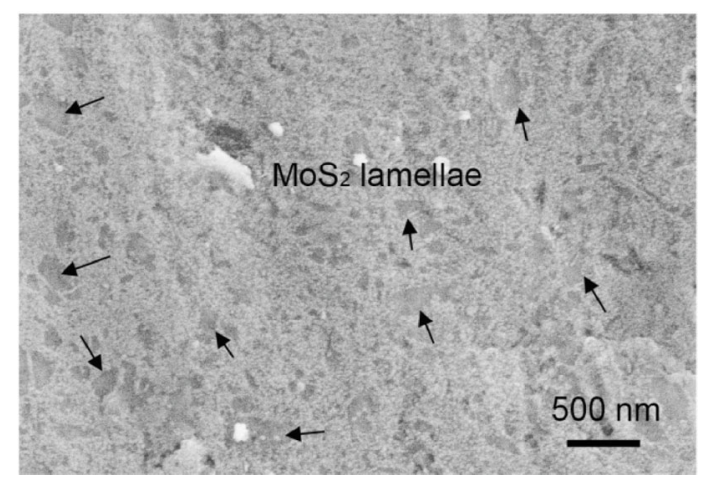

Fig. 5 FE-SEM image of worn surface of $\mathrm{Cu}-30-\mathrm{vol} \%-\mathrm{MoS}_{2}$ composite.

information from the surface and can be useful in identifying the lubricating film or sample compositions. As can be observed in Fig. 6, the elements of $\mathrm{Cu}$, $\mathrm{Mo}, \mathrm{S}$, and $\mathrm{O}$ are identified in the worn surfaces, and the corresponding characteristic peaks of $\mathrm{Cu} 2 \mathrm{p}$ (932.4 eV), Mo3d (228.7 eV), S2p (162.2 eV), and O1s
$(530.3 \mathrm{eV})$ are marked. It is evident that the intensities of the S2p and Mo3d peaks increase as the content of $\mathrm{MoS}_{2}$ increases in the composites. The survey spectra of all the composites shift in the first few hundreds of seconds of etch time and then remain mostly unchanged with further etching. This indicates that the composition of the outmost surface is vastly different from that of the internal surface. Hence, it is confirmed that there is a $\mathrm{MoS}_{2}$ lubricating film formed on the worn surfaces of the $\mathrm{Cu}-\mathrm{MoS}_{2}$ composites. In order to quantitative study the elemental evolution at the surface, the survey spectra from the original data set of 7-11 scans were then peak fitted at each etch level to obtain a full atomic percent quantification throughout the sample depth.

The quantitative analysis of the elements in the worn surface distributed in the depth direction is presented in Fig. 7. It can be observed in Fig. 7(a) that the atomic percentage of $\mathrm{Cu}$ increases to a maximum value and then remains constant as the etch time increases, while the content of $\mathrm{O}$ changes in the opposite direction. The reason for the high oxygen content in the outmost surfaces is the oxidation of copper matrix and $\mathrm{MoS}_{2}$ during friction under atmosphere environment. It is interesting to note in Fig. 7 that the atomic percentage of Mo and S greatly increases first and then gradually decreases with the increase in etch time; this is especially evident in Figs. 7(d) and 7(e). The low content of Mo and S in the outmost surface may be attributed to the high content of $\mathrm{O}$. It is well known that the sputtering rate of different elements varies greatly $[37,38]$. In the majority of cases, the greater the atomic mass of the element is, the lower the sputtering rate. The sputtering rate of $S$ is higher than that of $\mathrm{Cu}$ and even higher than that of Mo. Hence, sputtering may result in a modification of the surface composition. However, the previous investigation on $\mathrm{MoS}_{2}$ sputtering showed that the $\mathrm{S}$ concentration decreased from 67 at $\%$ to 63 at $\%$ after a sputtering time of 20 mins with a $3-\mathrm{keV} \mathrm{Ar}^{+}$ion beam [37]. This indicates that the sputtering has a low impact on the surface composition of $\mathrm{Cu}-\mathrm{MoS}_{2}$ composites considered in this study. As the $\mathrm{MoS}_{2}$ content increases from $5 \mathrm{vol} \%$ to $40 \mathrm{vol} \%$, the atomic percentages of Mo and S clearly increase, and the maximum value is obtained at a longer etch time. The maximum contents 

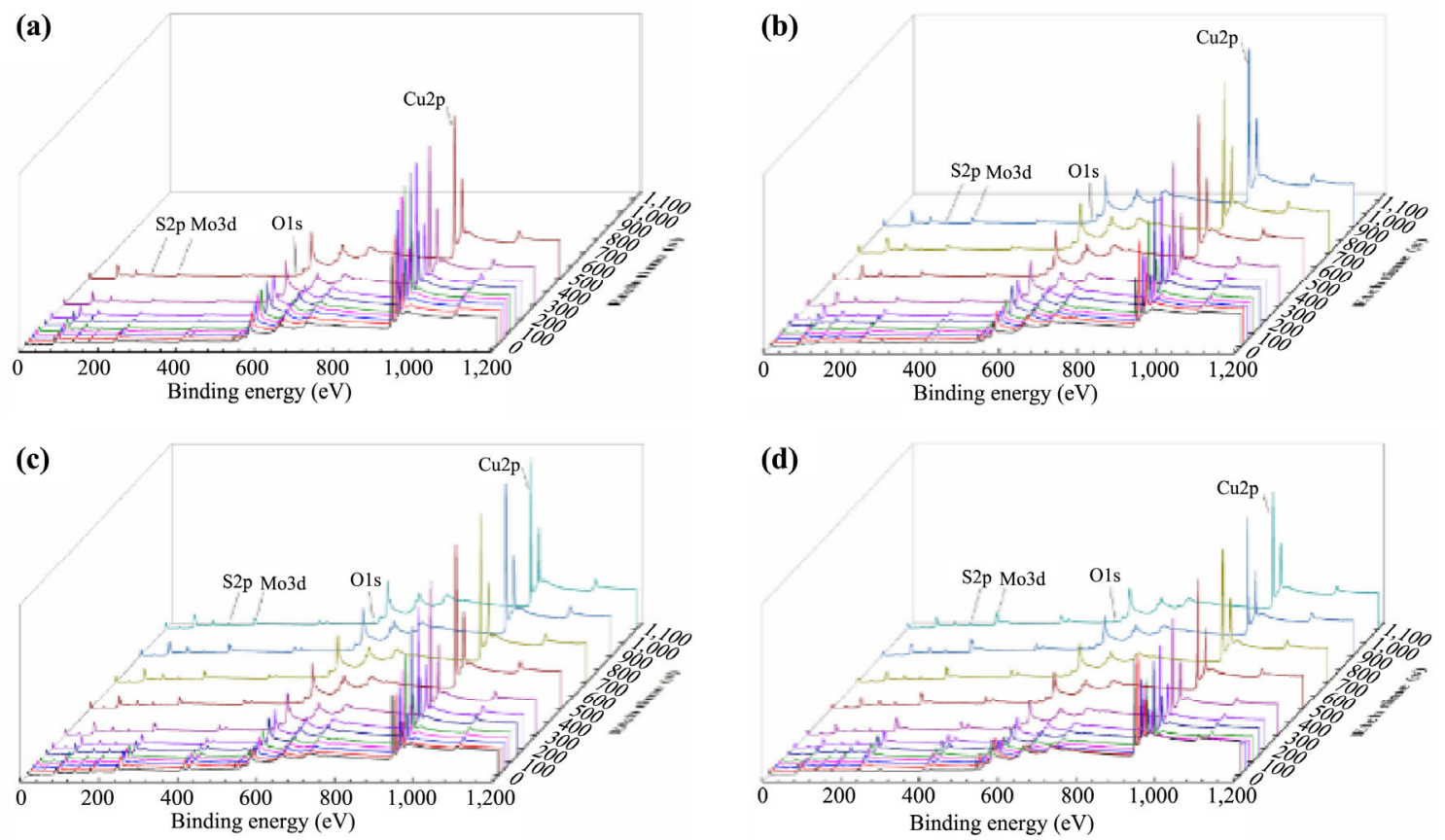

Fig. 6 Evolution of depth profile survey spectra of $\mathrm{Cu}-\mathrm{MoS}_{2}$ composites with $\mathrm{MoS}_{2}$ content of (a) 10 vol\%, (b) 20 vol\%, (c) 30 vol\%, and (d) 40 vol\%.

of $\mathrm{Mo}$ and $\mathrm{S}$ in $\mathrm{Cu}-5-\mathrm{vol} \%-\mathrm{MoS}_{2}$ and $\mathrm{Cu}-10-\mathrm{vol} \%-\mathrm{MoS}_{2}$ composites are obtained after approximately $50 \mathrm{~s}$ of etching as shown in Figs. 7(a) and 7(b), which to $100 \mathrm{~s}$ for $\mathrm{Cu}-20-\mathrm{vol} \%-\mathrm{MoS}_{2}, \mathrm{Cu}-30-\mathrm{vol} \%-\mathrm{MoS}_{2}$, and $\mathrm{Cu}-$ 40-vol\%-MoS 2 composites as shown in Figs. 7(c) and $7(\mathrm{~d})$. These results indicate that the worn surfaces of $\mathrm{Cu}-\mathrm{MoS}_{2}$ composites are enriched in $\mathrm{MoS}_{2}$. However, the volume fraction or the area coverage of the $\mathrm{MoS}_{2}$ lubricating film on the worn surfaces is yet to be determined, which is an essential characteristic for self-lubricating composites.

As the atomic percentages of all the elements in the surface of each etched layer are known, the volume fraction of each component can be calculated based on the following steps. Firstly, the weight of $\mathrm{Cu}, \mathrm{Mo}$, and $\mathrm{S}$ atoms can be determined by multiplying their atomic percentages by their relative atomic mass (63.5, 96 , and 32 , respectively), and the weight percentages of $\mathrm{Cu}, \mathrm{Mo}$, and $\mathrm{S}$ can then be calculated by dividing the weight of each atom by the total weight. Secondly, the volume of $\mathrm{MoS}_{2}$ was calculated by dividing the sum of the weight percentages of Mo and $S$ by the density of $\mathrm{MoS}_{2}\left(4.8 \mathrm{~g} / \mathrm{cm}^{3}\right)$, and the volume of $\mathrm{Cu}$ was calculated by dividing the weight percentage of $\mathrm{Cu}$ by the density of copper $\left(8.9 \mathrm{~g} / \mathrm{cm}^{3}\right)$. Finally, the volume fraction of $\mathrm{MoS}_{2}$ and $\mathrm{Cu}$ can be computed by dividing each volume by the sum volume of them. Figure 8 shows the evolution of the volume fraction of $\mathrm{MoS}_{2}$ in the worn surfaces as a function of the etch time. From the outmost surface to the subsurface, the $\mathrm{MoS}_{2}$ content first increases rapidly and then decreases slowly. The greatest content of $\mathrm{MoS}_{2}$ was obtained at the subsurface (10 nm-30 nm off the surface) and reached $26 \mathrm{vol} \%, 34 \mathrm{vol} \%, 41 \mathrm{vol} \%, 64 \mathrm{vol} \%$, and $65 \mathrm{vol} \%$ for the $\mathrm{Cu}-\mathrm{MoS}_{2}$ composites with $\mathrm{MoS}_{2}$ contents ranging from $5 \mathrm{vol} \%-40 \mathrm{vol} \%$. The content of $\mathrm{MoS}_{2}$ in the subsurface layer is apparently significantly higher than that in the composites. When the worn surfaces were etched for approximately $700 \mathrm{~s}(230 \mathrm{~nm})$, the content of the $\mathrm{MoS}_{2}$ was beginning to stabilize. At the end of the etching, the content of $\mathrm{MoS}_{2}$ reaches $10 \mathrm{vol} \%, 12 \mathrm{vol} \%, 22 \mathrm{vol} \%, 31 \mathrm{vol} \%$, and $45 \mathrm{vol} \%$ for the $\mathrm{Cu}-\mathrm{MoS}_{2}$ composites with $\mathrm{MoS}_{2}$ contents of $5 \mathrm{vol} \%-40 \mathrm{vol} \%$. Except for the Cu-5-vol\%-MoS composite, the $\mathrm{MoS}_{2}$ content of the other composites measured using XPS is very close to the actual added content, and the corresponding error is less than $8 \%$. Therefore, it can be demonstrated that the quantitative analysis of the coverage of the lubricating film or content of lubricant on the worn surface using XPS 

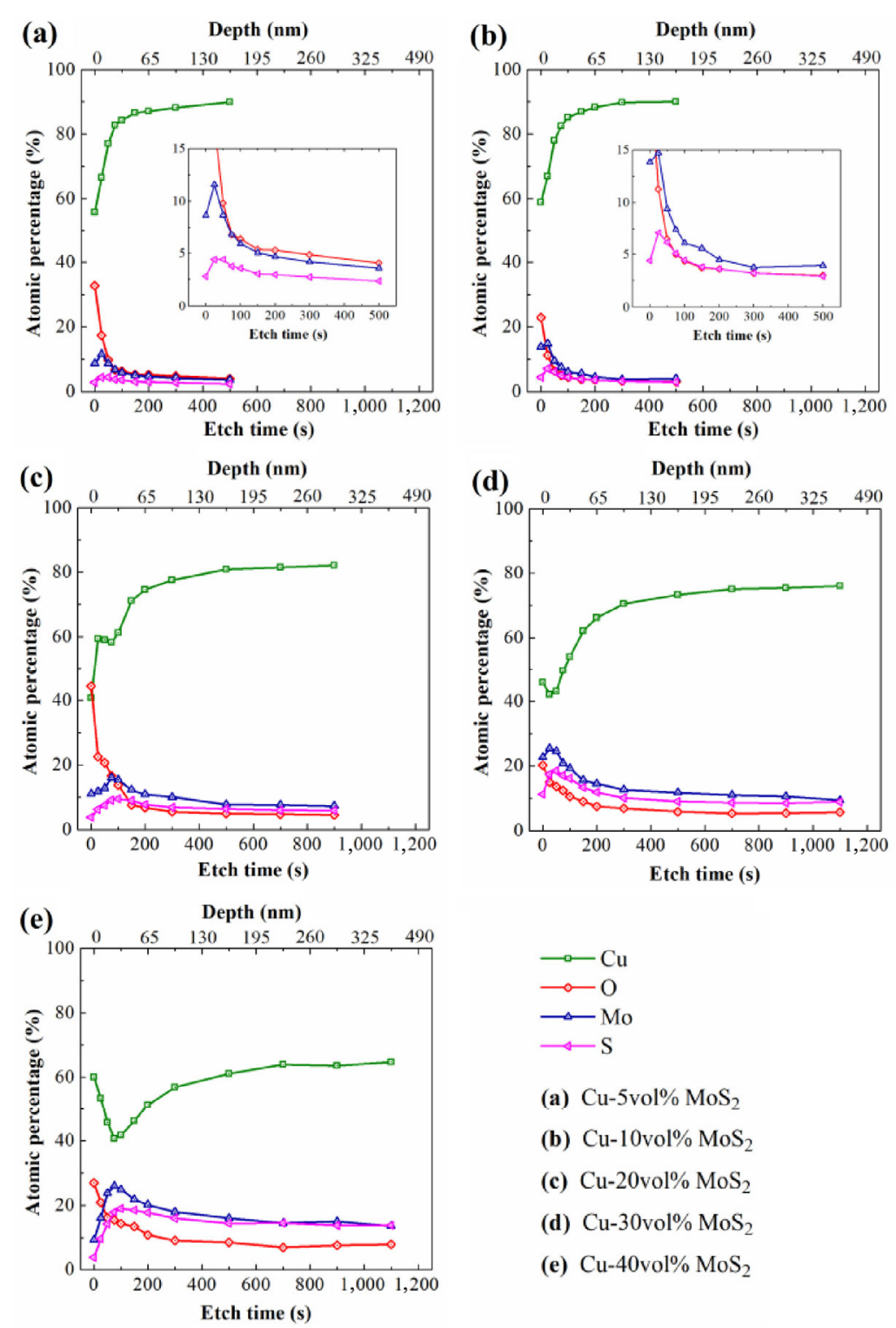
(a) $\mathrm{Cu}-5 \mathrm{vol} \% \mathrm{MoS}_{2}$
(b) $\mathrm{Cu}-10 \mathrm{vol} \% \mathrm{MoS}_{2}$
(c) $\mathrm{Cu}-20 \mathrm{vol} \% \mathrm{MoS}_{2}$
(d) $\mathrm{Cu}-30 \mathrm{vol} \% \mathrm{MoS}_{2}$
(e) $\mathrm{Cu}-40 \mathrm{vol} \% \mathrm{MoS}_{2}$

Fig. 7 Evolution of elemental atomic percentages in depth for $\mathrm{Cu}-\mathrm{MoS}_{2}$ composites with $\mathrm{MoS}_{2}$ content of (a) 5 vol\%, (b) 10 vol\%, (c) $20 \mathrm{vol} \%$, (d) $30 \mathrm{vol} \%$, and (e) $40 \mathrm{vol} \%$.

is feasible and reliable. The region with the highest content of $\mathrm{MoS}_{2}$ does not appear at the outmost surface as expected in Fig. 2 because the surface oxidation and adsorbed gas reduce the relative content of $\mathrm{MoS}_{2}$. The highest content of $\mathrm{MoS}_{2}$ appears at the depth of $10 \mathrm{~nm}-30 \mathrm{~nm}$ from the surface, and the depth tends to increase with the increase in the $\mathrm{MoS}_{2}$ content. The high content of $\mathrm{MoS}_{2}$ in the worn surface is due to the split of the lamellar structure of the $\mathrm{MoS}_{2}$ crystal during sliding, which results in the formation of many more and thinner $\mathrm{MoS}_{2}$ crystals and increases their surface area. Hence, a $\mathrm{MoS}_{2}$ lubricating film is formed on the worn surface in the form of $\mathrm{MoS}_{2}$ lamellae with a thickness from tens to hundreds of nanometers. During the etching process, the $\mathrm{MoS}_{2}$ lamellae of a few or tens of nanometers are preferentially etched, such that the $\mathrm{MoS}_{2}$ lamellae on the surface are gradually reduced. When the thin $\mathrm{MoS}_{2}$ lamellae produced by friction have been etched by $\mathrm{Ar}^{+}$ions, the $\mathrm{MoS}_{2}$ content on the surface approaches that added to the composite. The evolution of the $\mathrm{MoS}_{2}$ content with the etch depth shown in Fig. 8 is in good agreement with the expected trend shown in Fig. 2(c).

Although it is well known that the coverage of the 


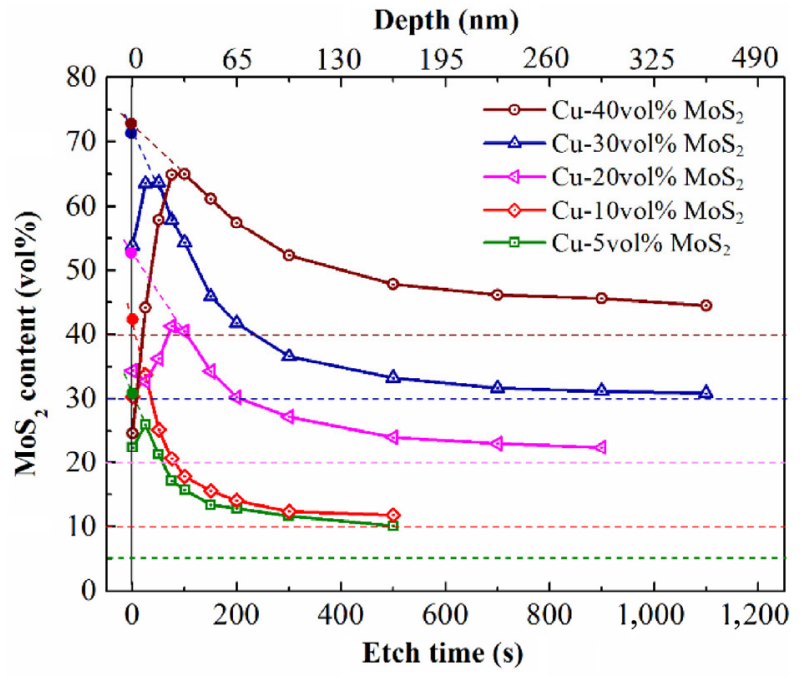

Fig. 8 Evolution of $\mathrm{MoS}_{2}$ content with depth for $\mathrm{Cu}-\mathrm{MoS}_{2}$ composites.

lubricating film on the worn surface increases as the lubricant content increases, it is still unclear whether their relationship follows a linear law. Here, the content of $\mathrm{MoS}_{2}$ on the outmost surface was predicted according to the changing trend as indicated in Fig. 8. The $\mathrm{MoS}_{2}$ contents in the outmost surfaces are expected to be $31 \mathrm{vol} \%, 42 \mathrm{vol} \%, 53 \mathrm{vol} \%, 72 \mathrm{vol} \%$, and $73 \mathrm{vol} \%$ (indicated by the solid dot in Fig. 8) for $\mathrm{Cu}-\mathrm{MoS}_{2}$ composites with a $\mathrm{MoS}_{2}$ content of $5 \mathrm{vol} \%-40 \mathrm{vol} \%$. The $\mathrm{MoS}_{2}$ content on the outmost surface is equal to the coverage of the $\mathrm{MoS}_{2}$ lubricating film. Figure 9 illustrates the influence of the volume fraction of $\mathrm{MoS}_{2}$ in the composites on the coverage of $\mathrm{MoS}_{2}$ film on the worn surfaces. With the increase in the $\mathrm{MoS}_{2}$ content in the composites, the coverage of the $\mathrm{MoS}_{2}$ film on the worn surface increases gradually, but the increasing rate reduces. In order to discover the relationship between the $\mathrm{MoS}_{2}$ content in composite and the $\mathrm{MoS}_{2}$ content in worn surface, Origin 9 software was used to fit the experimental data. The fitted line is presented in Fig. 9, and it satisfies the exponential equation of $\alpha_{\mathrm{f}}=22 V^{0.33}$. Thus, the coverage of the lubricating film does not have a linear but an exponential relationship with the lubricant content. Apparently, when the composites have a relatively low content of $\mathrm{MoS}_{2}$ ( $5 \mathrm{vol} \%$ or $10 \mathrm{vol} \%$ ), the copper matrix surface can supply sufficient space for the slip and adhesion of $\mathrm{MoS}_{2}$ lamellae, which contributes to the formation of a large area of the lubricating film. The included $\mathrm{MoS}_{2}$ then exhibits a very high efficiency of lubrication. For

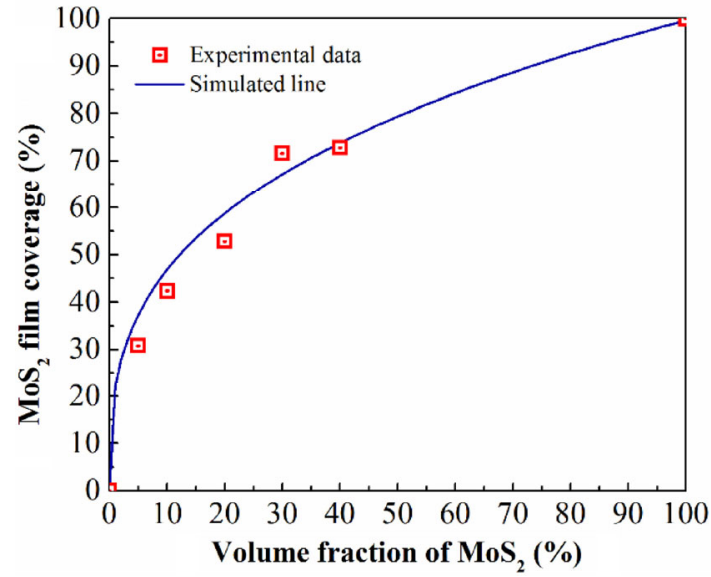

Fig. 9 Influence of volume fraction of $\mathrm{MoS}_{2}$ in composites on $\mathrm{MoS}_{2}$ film coverage on outmost worn surfaces.

composites of high $\mathrm{MoS}_{2}$ content (20 vol\%-40 vol\%), a further addition of $\mathrm{MoS}_{2}$ cannot be effective in generating more new $\mathrm{MoS}_{2}$ lamellae, and the rate of increase in the coverage of the $\mathrm{MoS}_{2}$ film is then reduced. To directly demonstrate the lubricating effect of $\mathrm{MoS}_{2}$, the ratio of the film coverage to the volume fraction of the lubricant $(k)$ is calculated using Eq. (1). The value of $k$ decreases from 6.2 to 2.9 when the $\mathrm{MoS}_{2}$ content increases from $5 \mathrm{vol} \%$ to $40 \mathrm{vol} \%$. This result confirms that the lubricating efficiency of the lubricant decreases with the increase in the lubricant content in the composite.

The friction coefficients of the $\mathrm{Cu}-\mathrm{MoS}_{2}$ composites with various $\mathrm{MoS}_{2}$ contents were obtained in the friction tests. The coverage of the $\mathrm{MoS}_{2}$ film in the outmost surfaces was also acquired using XPS, as illustrated in Fig. 7. Hence, the relationship between the friction coefficient and $\mathrm{MoS}_{2}$ film coverage could be established, and it is shown in Fig. 10(a). With the increase in the coverage area of the $\mathrm{MoS}_{2}$ film on the worn surface, the surface friction is alleviated, and the friction coefficient decreases. The solid line in Fig. 10(a) was plotted based on Eq. (5) with the equation of $\mu=\left(1-\alpha_{\mathrm{f}}\right)^{2} \times 0.76+\left(1-\left(1-\alpha_{\mathrm{f}}\right)^{2}\right) \times 0.1$. The value of $\mu_{\mathrm{m}}$ in Eq. (5) is selected from the friction coefficient of pure copper (0.76), and the value of $\mu_{\mathrm{f}}$ is assigned as 0.1 as the friction coefficient of the $\mathrm{MoS}_{2}$ pin according to some literatures $[12,13,28]$. It can be observed that the experimental data agrees well with Eq. (5). Figure 10(b) presents the influence of the volume fraction of $\mathrm{MoS}_{2}$ on the friction coefficient of the composites. The friction coefficient decreases quickly 

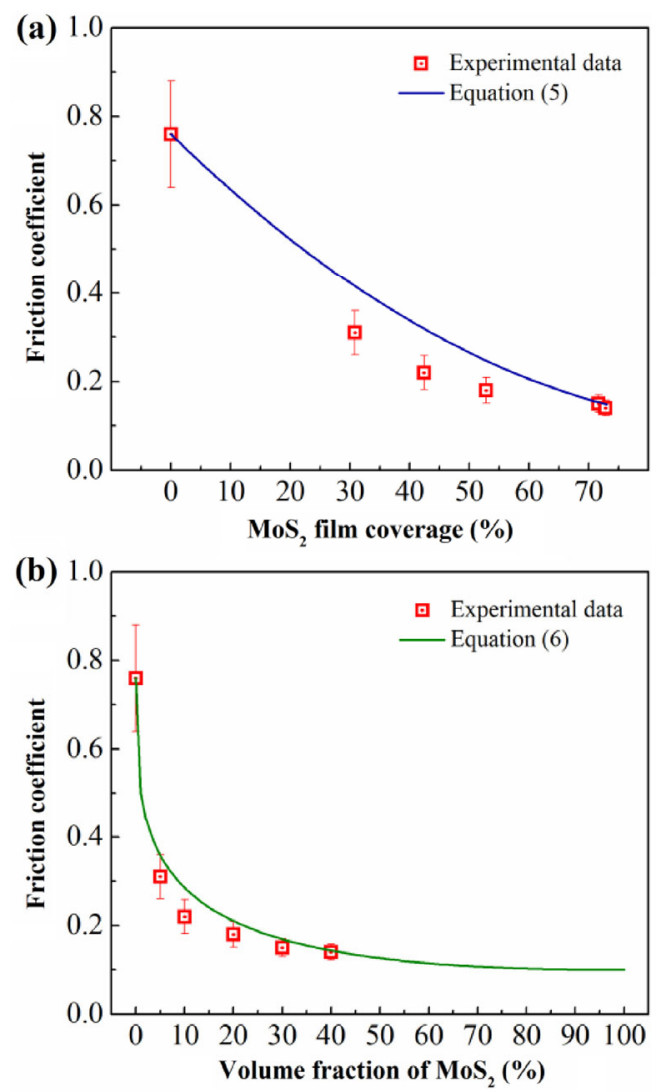

Fig. 10 Variations of friction coefficient of $\mathrm{Cu}-\mathrm{MoS}_{2}$ composites with (a) $\mathrm{MoS}_{2}$ film coverage and (b) volume fraction.

from 0.76 of pure copper to $\mathrm{Cu}-20-\mathrm{vol} \%-\mathrm{MoS}_{2}$ of 0.18 and decreases slowly with the further addition of $\mathrm{MoS}_{2}$ in the composite. The solid line in Fig. 10(b) was plotted according to Eq. (6) with the equation of $\mu=\left(1-22 V^{0.33}\right)^{2} \times 0.76+\left(1-\left(1-22 V^{0.33}\right)^{2}\right) \times 0.1$. The values of $\mu_{\mathrm{m}}$ and $\mu_{\mathrm{f}}$ in Eq. (6) are the same as those in Eq. (5). The experimental data is in good agreement with the equation. The variation of the friction coefficient with the lubricant content is also in agreement with many other MMSCs [10, 11, 13]. Therefore, the relationships among the friction coefficient, coverage of lubricating film, and volume fraction of the lubricant can be successfully established via the quantitative characterization of the worn surface using XPS.

\section{Conclusions}

The present study is focused on the development of a friction model for MMSCs. An XPS analysis with depth profiling was developed and successfully implemented for quantitatively characterizing the coverage of the lubricating film. The $\mathrm{MoS}_{2}$ lubricating film on the worn surface of $\mathrm{Cu}-\mathrm{MoS}_{2}$ composites comprises several $\mathrm{MoS}_{2}$ lamellae of size less than $200 \mathrm{~nm}$. The $\mathrm{MoS}_{2}$ content gradually decreases from the outmost surface to the matrix, and the coverage of the $\mathrm{MoS}_{2}$ film on the outmost surface is 2.9-6.2 times that of the matrix. The coverage of the $\mathrm{MoS}_{2}$ film has an exponential relationship with the $\mathrm{MoS}_{2}$ volume content, which can explain why adding too much lubricant does not significantly reduce the friction coefficient. Based on the quantitative characterization of the film coverage, the relationships among the friction coefficient, coverage of lubricating film, and volume fraction of lubricant are successfully established, and the developed friction model for the MMSC is verified.

\section{Acknowledgments}

The authors would like to thank the National Natural Science Foundation of China (Grant No. 51804272), Natural Science Foundation of Jiangsu Province (Grant No. BK20160472), Natural Science Foundation of the Jiangsu Higher Education Institutions of China (Grant No. 17KJB460017), Project funded by China Postdoctoral Science Foundation (Grant No. 2018M640526), Jiangsu Planned Projects for Postdoctoral Research Funds (Grant No. 1601095C and 2018K073C), Postgraduate Research \& Practice Innovation Program of Jiangsu Province (Grant No. SJCX17_0623), Marine Science and Technology Project of Jiangsu Province (Grant No. HY2017-10), Cooperation Funding of Yangzhou City-Yangzhou University (Grant No. YZU201722), and Jiangdu Advanced Equipment Engineering Institute of Yangzhou University (Grant No. 2017-01) for the financial support provided.

Open Access This article is licensed under a Creative Commons Attribution 4.0 International License, which permits use, sharing, adaptation, distribution and reproduction in any medium or format, as long as you give appropriate credit to the original author(s) and the source, provide a link to the Creative Commons licence, and indicate if changes were made.

The images or other third party material in this article are included in the article's Creative Commons 
licence, unless indicated otherwise in a credit line to the material. If material is not included in the article's Creative Commons licence and your intended use is not permitted by statutory regulation or exceeds the permitted use, you will need to obtain permission directly from the copyright holder.

To view a copy of this licence, visit http://creativecommons.org/licenses/by/4.0/.

\section{References}

[1] Su Y F, Zhang Y S, Song J J, Hu L T. Tribological behavior and lubrication mechanism of self-lubricating ceramic/metal composites: The effect of matrix type on the friction and wear properties. Wear 372-373: 130-138 (2017)

[2] Sharma S M, Anand A. Solid lubrication in iron based materials-a review. Tribol Ind 38(3): 318-331 (2016)

[3] De Mello J D B, Binder C, Hammes G, Binder R, Klein A N. Tribological behaviour of sintered iron based self-lubricating composites. Friction 5(3): 285-307 (2017)

[4] Scharf T W, Prasad S V. Solid lubricants: A review. J Mater Sci 48(2): 511-531 (2013)

[5] Chhowalla M, Amaratunga G A J. Thin films of fullerenelike $\mathrm{MoS}_{2}$ nanoparticles with ultra-low friction and wear. Nature 407(6801): 164-167 (2000)

[6] Wang W, Xie G X, Luo J B. Black phosphorus as a new lubricant. Friction 6(1): 116-142 (2018)

[7] Shiao S J, Wang T Z. Dry self-lubricating composites. Compos: Part B 27(5): 459-465 (1996)

[8] Xiao J K, Zhang L, Zhou K C, Wang X P. Microscratch behavior of copper-graphite composites. Tribol Int 57: 38-45 (2013)

[9] Mahathanabodee S, Palathai T, Raadnui S, Tongsri R, Sombatsompop N. Dry sliding wear behavior of SS316L composites containing h-BN and $\mathrm{MoS}_{2}$ solid lubricants. Wear 316(1-2): 37-48 (2014)

[10] Kováčik J, Emmer Š, Bielek J, Keleši L. Effect of composition on friction coefficient of $\mathrm{Cu}$-graphite composites. Wear 265(3-4): 417-421 (2008)

[11] Akhlaghi F, Zare-Bidaki A. Influence of graphite content on the dry sliding and oil impregnated sliding wear behavior of Al 2024-graphite composites produced by in situ powder metallurgy method. Wear 266(1-2): 37-45 (2009)

[12] Wu Y X, Wang F X, Cheng Y Q, Chen N P. A study of the optimization mechanism of solid lubricant concentration in $\mathrm{NiMoS}_{2}$ self-lubricating composite. Wear 205(1-2): 64-70 (1997)

[13] Xiao J K, Zhang W, Liu L M, Zhang L, Zhang C. Tribological behavior of copper-molybdenum disulfide composites. Wear
384-385: 61-71 (2017)

[14] Rohatgi P K, Liu Y, Yin M, Barr T L. Tribological behavior and surface analysis of tribodeformed AI alloy-50 pet graphite particle composites. Metall Trans A 22(6): 1435-1441 (1991)

[15] Axén N, Hutchings I M, Jacobson S. A model for the friction of multiphase materials in abrasion. Tribol Int 29(6): 467-475 (1996)

[16] van Trinh P, Trung T B, Thang N B, Thang B H, Tinh T X, Quang L D, Phuong D D, Minh P N. Calculation of the friction coefficient of $\mathrm{Cu}$ matrix composite reinforced by carbon nanotubes. Comp Mater Sci 49(4 Suppl 1): S239-S241 (2010)

[17] Song J P, Valefi M, de Rooij M, Schipper D J. A mechanical model for surface layer formation on self-lubricating ceramic composites. Wear 268(9-10): 1072-1079 (2010)

[18] Valefi M, de Rooij M, Mokhtari M, Schipper D J. Modelling of a thin soft layer on a self-lubricating ceramic composite. Wear 303(1-2): 178-184 (2013)

[19] Xu Z S, Zhang Q X, Huang X J, Liu R, Zhai W Z, Yang K, Zhu Q S. An approximate model for the migration of solid lubricant on metal matrix self-lubricating composites. Tribol Int 93: 104-114 (2016)

[20] Bowden F P, Tabor D. The Friction and Lubrication of Solids. Oxford (UK): Clarendon Press, 1964.

[21] Sawyer W G, Dickrell P L. A fractional coverage model for gas-surface interaction in reciprocating sliding contacts. Wear 256(1-2): 73-80 (2004)

[22] Pudjoprawoto R, Dougherty P, Higgs III C F. A volumetric fractional coverage model to predict frictional behavior for in situ transfer film lubrication. Wear 304(1-2): 173-182 (2013)

[23] Wornyoh E Y A, Higgs III C F. An asperity-based fractional coverage model for transfer films on a tribological surface. Wear 270(3-4): 127-139 (2011)

[24] Blanchet T A, Sawyer W G. Differential application of wear models to fractional thin films. Wear 251(1-12): 1003-1008 (2001)

[25] Ye J, Khare H S, Burris D L. Quantitative characterization of solid lubricant transfer film quality. Wear 316(1-2): 133-143 (2014)

[26] Haidar D R, Ye J, Moore A C, Burris D L. Assessing quantitative metrics of transfer film quality as indicators of polymer wear performance. Wear 380-381: 78-85 (2017)

[27] Cao H Q, Qian Z Y, Zhang L, Xiao J K, Zhou K C. Tribological behavior of $\mathrm{Cu}$ matrix composites containing graphite and tungsten disulfide. Tribol Trans 57(6): 1037-1043 (2014)

[28] Zhang L, Xiao J K, Zhou K C. Sliding wear behavior of silver-molybdenum disulfide composite. Tribol Trans 55(4): 473-480 (2012) 
[29] Rohatgi P K, Liu Y, Yin M, Barr T L. A surface-analytical study of tribodeformed aluminum alloy 319-10 vol.\% graphite particle composite. Mater Sci Eng A 123(2): 213-218 (1990)

[30] Mandrino D, Podgornik B. XPS investigations of tribofilms formed on CrN coatings. Appl Surf Sci 396: 554-559 (2017)

[31] Blau P J, Yust C S. Microfriction studies of model selflubricating surfaces. Surf Coat Technol 62(1-3): 380-387 (1993)

[32] Ma W L, Lu J J. Effect of surface texture on transfer layer formation and tribological behaviour of copper-graphite composite. Wear 270(3-4): 218-229 (2011)

[33] Wilson J E, Stott F H, Wood G C. The development of wearprotective oxides and their influence on sliding friction. Proc Roy Soc A: Mathem, Phys Eng Sci 369(1739): 557-574 (1980)

[34] Ghods P, Isgor O B, Brown J R, Bensebaa F, Kingston D. XPS depth profiling study on the passive oxide film of carbon steel in saturated calcium hydroxide solution and the effect of chloride on the film properties. Appl Surf Sci

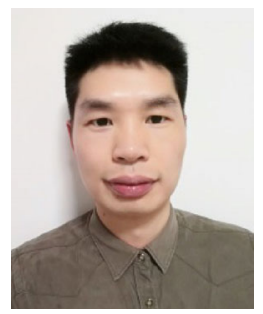

Jinkun XIAO. Assistant professor, obtained his bachelor degree and Ph.D degree in 2010 and 2015 from Central South University, majoring in material science and engineering. He worked as an assistant professor since 2015 at Yangzhou University.

His interested research areas include self-lubricating

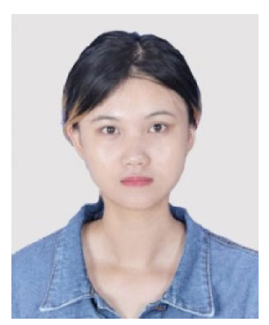

Yuqing WU. She received her bachelor degree in material processing and control engineering in 2017 from Yangzhou University. After then, she was a master student

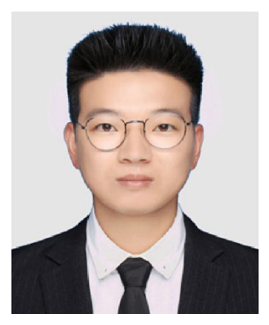

Wei ZHANG. He received his bachelor degree in metallic materials engineering in 2015 from Nanchang Hangkong University. He is cur-
257(10): 4669-4677 (2011)

[35] Chasoglou D, Hryha E, Norell M, Nyborg L. Characterization of surface oxides on water-atomized steel powder by XPS/ AES depth profiling and nano-scale lateral surface analysis. Appl Surf Sci 268: 496-506 (2013)

[36] Busby Y, List-Kratochvil E J W, Pireaux J J. Chemical analysis of the interface in bulk-heterojunction solar cells by $\mathrm{X}$-ray photoelectron spectroscopy depth profiling. ACS Appl Mater Interfaces 9(4): 3842-3848 (2017)

[37] Baker M A, Gilmore R, Lenardi C, Gissler W. XPS investigation of preferential sputtering of $\mathrm{S}$ from $\mathrm{MoS}_{2}$ and determination of $\mathrm{MoS}_{x}$ stoichiometry from Mo and S peak positions. Appl Surf Sci 150(1-4): 255-262 (1999)

[38] Steinberger R, Walter J, Greunz T, Duchoslav J, Arndt M, Molodtsov S, Meyer D C, Stifter D. XPS study of the effects of long-term $\mathrm{Ar}^{+}$ion and Ar cluster sputtering on the chemical degradation of hydrozincite and iron oxide. Corros Sci 99: 66-75 (2015)

composites, metal matrix friction materials, wearresistant coatings, powder metallurgy and thermal spray technology. He has published more than 20 papers on international journals. He presided and participated in many research projects like "National Natural Science Foundation of China", "Natural Science Foundation of Jiangsu Province", and some cooperation projects.

in material processing engineering at the same university. Her interested research areas include wear-resistant coatings, high-entropy alloy and thermal spray technology.

rently pursuing his master degree at Yangzhou University. His interested research areas include metal matrix self-lubricating composites and thermal spray technology. 


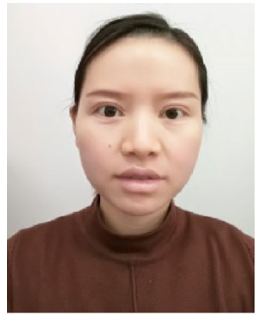

Juan CHEN. Assistant professor, obtained her bachelor degree in 2010 from Xi'an Polytechnic University and Ph.D degree in 2016 from Central South University, majoring in material science and engineering. She worked as an assistant professor, since 2017 at Yangzhou University. Her

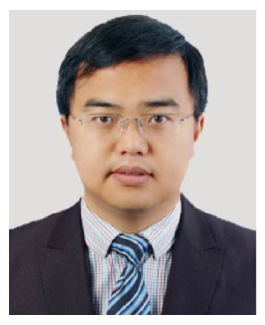

Chao ZHANG. Professor, obtained his bachelor degree from Chongqing University in 2003 and his Ph.D degree from Technology University of Belfort-Montbéliard and Xi'anJiaotong University in June 2008. From September 2007 to January 2009, he worked as a teaching-research assistant in Technology University of Belfort-Montbéliard. Since February 2009, he is a postdoctoral researcher, interested research areas include wear-resistant alloys, superalloys, thermodynamic, kinetic, microstructure, scanning electron microscope and transmission electron microscope. She presided and participated in many research projects like "National Natural Science Foundation of China" and "China Postdoctoral Science Foundation". She has published more than 10 papers on international journals.

and then a senior researcher in materials science Department of Engineering School of University of Mons. In 2014, he joined Yangzhou University as professor where he is leading a research group on thermal spray coatings and gas sensors. His research interests include thermal sprayed techniques and coatings, especially gas sensing and wear-resistant coatings. He has published more than 70 papers on international journals. 